\title{
Predicting the characteristic parameters of shale sweet-spot with complex resistivity
}

\author{
Feng-Jiao Xu ${ }^{1,2}$, Liang-Jun Yan ${ }^{1,2, *}$, Kui Xiang ${ }^{1,2}$, Xiao-Long Tong ${ }^{1,2}$, and Xing-Bing Xie ${ }^{1,2}$ \\ ${ }^{1}$ Hubei Cooperative Innovation Center of Unconventional Oil and Gas, Yangtze University, Hubei, China \\ ${ }^{2}$ Key Laboratory of Exploration Technologies for Oil and Gas Resources (Yangtze University), Ministry of Education, Hubei, \\ China
}

\begin{abstract}
Article history:
Received 4 August 2018

Revised 24 April 2019

Accepted 22 March 2020

Keywords:

Complex resistivity, Sweet-spots, Chargeability, TOC, Brittleness

\section{Citation:}

Xu, F.-J., L.-J. Yan, K. Xiang, X.-L. Tong, and X.-B. Xie, 2020: Predicting the characteristic parameters of shale sweet-spot with complex resistivity. Terr. Atmos. Ocean. Sci., 31, 497-505, doi: 10.3319/TAO.2020.03.22.01
\end{abstract}

\begin{abstract}
It is important to predict the capacity related parameters of reservoir such as brittleness, total organic carbon (TOC), in-situ stress, maturity of organic carbon (Ro), and buried depth in shale gas exploration and exploitation. Among these parameters, brittleness and TOC are especially important for shale gas exploitation. The complex resistivity measurement and analysis show that the rich organic shale in southern China features low resistivity and high chargeability. These characteristics are a geophysical prerequisite for predicting the sweet spot characteristic parameters of shale, such as TOC and brittleness, with rapid developing of high resolution controlled source electromagnetic (CSEM) method prospecting which can give resistivity and chargeability distribution of underground. Based on the rich organic shale composition analysis and complex resistivity measurements in southern China, this paper analysed the presence of pyrite as an associated mineral in organic-rich shale, and examined its relationship to resistivity, chargeability, TOC content and brittleness, and the quantitative relationship between the models has been established. Therefore, this study provides a firm experimental foundation for predicting parameters of shale sweet spots with CSEM prospecting.
\end{abstract}

\section{INTRODUCTION}

The region in shale gas reservoir with good features of successful shale resource play is often referred to as 'Sweet Spot'. Sweet spot exploration and predicting its characteristic parameters are significant for the horizontal well layout, the designing for well trajectory, the optimization of fracturing scheme and the evaluation of fracturing effect. Sweet spot can be identified based on the maturation of organic carbon (Ro), gas-bearing possibility, buried depth, thickness of shale, cracks and fissures possibility, total organic carbon (TOC), mineral composition, brittleness, and pressure distribution (Tsai et al. 2008; Chopra et al. 2012). Among these parameters, brittleness and TOC evaluation are especially important because they affect the elasticity and geo-mechanical properties of sweet spot. High resolution seismic exploration is an important method in predicting the gas reservoir (Wang et al. 2013). However, for the rugged topography and

\footnotetext{
* Corresponding author

E-mail:yljemlab@163.com
}

complicated geological condition and the ambiguous seismic characteristic, it is difficult to get high quality information with seismic exploration and has high costs for shale gas prospecting in southern China. On the other hand, controlled source electromagnetic (CSEM) method has played an important role in oil and gas exploration as an effective supplement technology to seismic exploration because of its advantages of great exploration depth, high efficiency, low cost, good adaptability, and direct detection of oil and gas. In recent years, the theoretical and experimental studies (Zhang et al. 2013; Xiang et al. 2014; Yan et al. 2014) found that the rich organic shale is characterized by low resistance and high chargeability and the difference of electric characteristics is superior to seismic velocity. Thus, the physical basis of electromagnetic method in predicting shale gas sweet spot is superior to the seismic method and has great potential applications in the future.

Rock is an aggregate of minerals and is a complex heterogeneous medium. Electromagnetic induction and induced polarization (IP) effect will affect rock properties 
under low frequency electromagnetic field conditions. Research on the induced polarization based on the electronic polarization mechanism of the conductor is rich and relatively mature (Luo and Zhang 1988; Li 1994). In contrast, research and experiment on the induced polarization based on the membrane polarization mechanism are complicated and lack systemic results. Thus, the validity of IP method in predicting shale gas becomes a hot research. Veeken et al. (2009) carried out the experimental research on the IP effect on rich organic shale. They obtained the dispersive curve of test samples and made the model fitting with the ColeCole model. Passey et al. (1990) observed that there was a closely relationship between shale gas resistivity, TOC, and Ro by rock resistivity measurement. Schön (2004) obtained the laminated shale and sandstone interbedded resistivity calculation model. Streich et al. (2010) introduced the shale gas exploration test using the CSEM in Germany and realised that the test had achieved good results only by making well data constraints. Nie (2014) concluded from his research that the resistivity of shale rock decreases with increasing rock mineral content and pyrite content, and increases with increasing rock organic matter content by employing a three-dimensional digital core forward modelling of shale gas reservoirs. Xiang et al. (2014) found that the rich organic shale in southern China has characteristics of low resistivity and high chargeability through a large number of the electrical measurement and analysis. They were also able to establish the relationship of chargeability, pyrite content, and TOC, and proposed the electromagnetic prospecting model for shale gas.

However, there is still few literatures about whether brittleness can be predicted by electromagnetic prospecting methods. The brittleness of shale is related to the composition of minerals, such as quartz and pyrite (Xiang et al. 2016; Ren et al. 2018). Although the content of pyrite is relatively small in rich-organic shale, but the influence on conductivity is great. Therefore, based on the composition analysis, this paper focused on the study of the relationship between resistivity, chargeability to the TOC and the brittleness of rich organic shale.

\section{SITE DESCRIPTION AND AVAILABLE DATASET}

The Southern China have more sets of shale formation and a large number of studies have been carried out in the area on rock samples from shale gas reservoirs (Yan et al. 2014). The shale in the Silurian Longmaxi formation to the Ordovician Wufen formation and the lower Cambrian Qiongzhusi formation have rich organic matter, high maturity and good conditions for storage of shale gas. Therefore, 30 shale samples collected from the outcrop and 17 shale cores from drilling well in southern china were used for the analysis of mineral composition and the characteristic parameters relationship of shale sweet-spot. The lithologic character of the shale samples is shown in Table 1.

$\mathrm{X}$-ray diffraction measurement and the mineral components analysis were done on the outcrop of shale samples from Longmaxi and Qiongzhusi formation. Figure 1 shows that the average content of brittle mineral (quartz, potash feldspar, plagioclase, and pyrite) in shale samples is about $60 \%$, while the average content in clay minerals is $36.2 \%$. In all the shale samples the pyrite has been discovered in rich percentage (around 5\%) which is a very typical mineral in the shale, and is also important for induced polarization.

At the same time, we carried out the complex resistivity test of the rock sample under the condition of saturated water and hence the amplitude and phase of complex resistivity can be obtained. In addition, by inverting the test data, the IP parameters associated with the shale gas reservoir can also be obtained. Combined with the results of the mineral components analysis, we can predict the TOC and brittleness of the shale rock. The detailed flow chart for the predicting for the characteristic parameters of sweet spot is shown in Fig. 2.

\section{METHODOLOGY}

\subsection{IP Mechanism of Rich-Organic Shale}

Induced polarization (IP) is a current-stimulated electrochemical phenomenon observed as decayed voltage response in earth materials. Membrane polarization and electrode polarization are two main mechanisms of rock polarization. The surface of clays and some other fibrous minerals are negatively charged and cause membrane polarization in rocks with small pore spaces. The static contact potentials between metallic conductors and electrolytes, and the additional over-voltages when currents flow through the interface cause electrode polarization. Although, for equivalent areas of active surface, electrode polarization is the strongest mechanism, clays are much more abundant than sulphides and hence most observed IP effects are due to membrane polarization (Wilson 2003).

\subsection{Spectrum Parameters Inversion}

In order to study the relationship of IP parameters with TOC and brittleness, the IP spectrum parameters of shale should be inverted based on measured complex resistivity data in laboratory. This can be achieved through introduction of certain kinds of complex resistivity models for this procession. Based on Cole-Cole dielectric dispersion model (Cole and Cole 1941), many other empirical models have been employed to fit the complex electrical response of rocks and soils. Yan et al. (2014) attest that the relaxation model from Pelton et al. (1978) is one of the most used model in which the resistivity of the mineralized porous rock is expressed as: 
$\rho(\omega)=\rho_{0}\left\{1-m\left[1-\frac{1}{1+(i \omega \tau)^{c}}\right]\right\}$

Where $\rho(\omega)$ represents the complex resistivity, $\rho_{0}$ represents resistivity at zero frequency, $m$ represents the intrinsic chargeability of sedimentary rocks, $\tau$ represents the time decay constant of the IP potential, while $c$ represents the relaxation constant, $\omega$ represents the angular frequency, and $i$ is the imaginary number. In general, observation from experiments indicates that pyrite has lower conductivity, higher chargeability, and longer time decay constant, and is a mineral usually associated with strong IP effect which could be used to detect hydrocarbons, ores, and underground water
(Yan et al. 2014).

\subsection{Gauss-Newton Inversion Method}

The IP spectrum inverse problem presented in Eq. (1) can be written in the form of nonlinear equation accordingly as:

$\widehat{\rho}=F(\widehat{p}, \widehat{\omega})$

Where $F$ is nonlinear operator, and $\widehat{\rho}=\left(\rho_{1}, \rho_{2}, \ldots, \rho_{n}\right)^{T}$ is a vector of complex resistivity, $\hat{p}=\left(\rho_{0}, m, \tau, c\right)$ is the IP

Table 1. The lithologic characteristics of the shale samples.

\begin{tabular}{c|c|ccc}
\hline Sampling area & Sampling type & Stratum layer & Lithology & Number of sampling \\
\hline \multirow{6}{*}{ Sichuan Province } & \multirow{3}{*}{ Outcrop } & $\epsilon_{1} \mathrm{q}$ & Gray-black mudstone, shale & 18 \\
\cline { 2 - 5 } & \multirow{3}{*}{ Well } & $\mathrm{S}_{1} 1$ & Gray-black mudstone, shale & 12 \\
\cline { 3 - 5 } & & $\mathrm{P}_{2} \mathrm{l}$ & Carbonaceous mudstone & 1 \\
& $\mathrm{~S}_{2} 1^{1}$ & Carbonaceous mudstone & 4 \\
& $\mathrm{~S}_{1} 1$ & Gray-black mudstone, shale & 9 \\
& & $\mathrm{O}_{3} \mathrm{~W}$ & Black shale & 3 \\
\hline
\end{tabular}

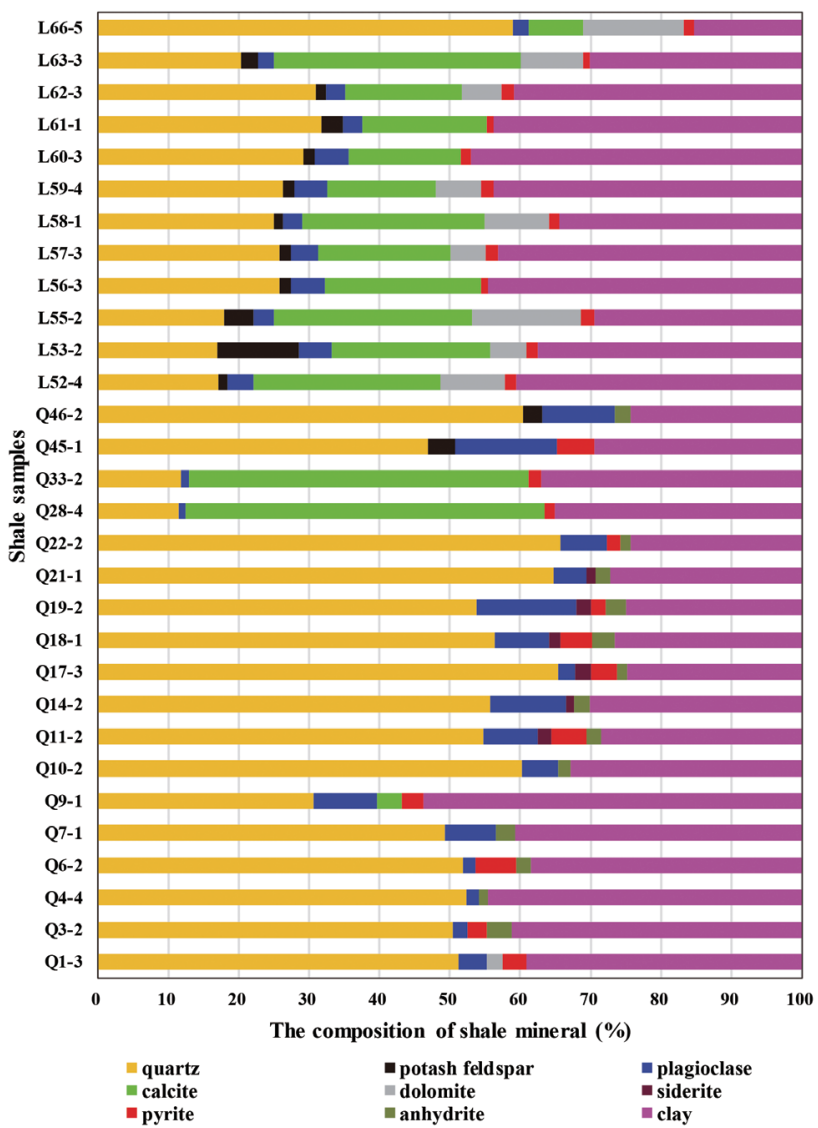

Fig. 1. Mineral composition of shale from $\mathrm{S}_{1} 1-\mathrm{O}_{3} \mathrm{w}$ and $\mathrm{C} 1 \mathrm{n}$ (red: pyrite). 


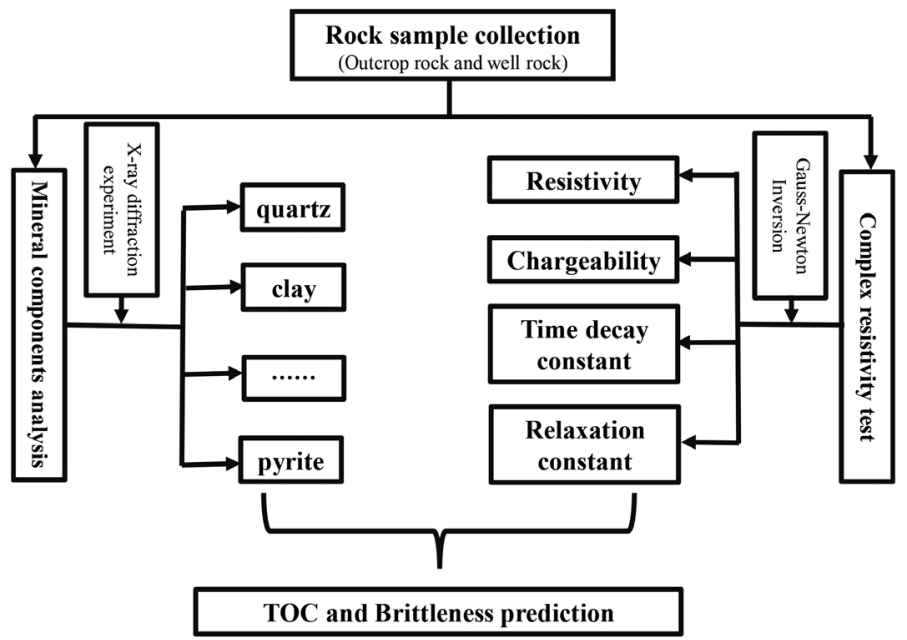

Fig. 2. Flowchart of TOC and Brittleness prediction.

true parameters, and $\widehat{\omega}=\left(\omega_{1}, \omega_{2}, \ldots, \omega_{n}\right)^{T}$ is the vector of angular frequency of measuring.

Considering the sharpness and multiscale of model parameters, object function can be written in the form of:

$$
E=e^{T} e=\left(\widehat{\rho}-\hat{\rho}_{s}\right)^{T}\left(\widehat{\rho}-\hat{\rho}_{s}\right)
$$

Where $\hat{\rho}_{s}$ is a vector of the observed complex resistivity. By using Gauss-Newton inversion method (Wang 2002) the inverse problem could depend on the solution of linear matrix equation iterating from initial model:

$$
A A^{T} \Delta \widehat{p}=A^{T} \Delta \widehat{\rho}
$$

Where: $\Delta \hat{p}=\hat{p}-\hat{p}_{0}, \Delta \hat{p}$ is a modified vector that reduces the objective function to a minimum direction, and of which analytic solution can be obtained according to Eq. (1). $\Delta \widehat{\rho}=\widehat{\rho}_{s}-\hat{\rho}\left(\widehat{\rho}_{0}\right), \Delta \hat{\rho}$ is the vector of calculated value for the difference between the measured complex resistivity data and the forward data. $A$ is a Jacobian matrix, and its formula is given by:

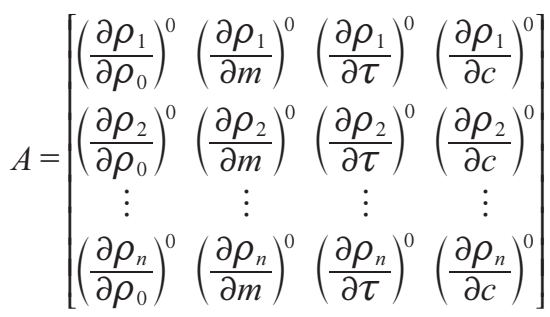

Obviously, $\widehat{\rho}$ is a nonlinear function of $\widehat{p}$ and $\widehat{\omega}$, by several linear Gauss-Newton iterations, the optimum inverted model will be reached.
Although Gauss-Newton method is largely dependent on initial model and can easily fall into the local minimum value, we can assume that the approximate range of the initial model parameters based on the experimental study in the research area.

\section{RESULTS}

\subsection{Model Testing}

We used the Cole-Cole model to check the feasibility of the inversion. First, we modelled the theoretical complex resistivity curve based on the Cole-Cole model parameters: $\rho_{0}$ $=500.0(\Omega \cdot \mathrm{m}), m=0.5, \tau=1.0 \times 10^{-3}(\mathrm{~s}), c=0.5$. Second, we added the $5 \%$ random interference to the complex resistivity curve. Finally, the true IP parameters $\left[\rho_{0}=501.24(\Omega \cdot \mathrm{m}), m\right.$ $\left.=0.4994, \tau=8.36 \times 10^{-4}(\mathrm{~s}), c=0.48\right]$ were obtained by the Gauss-Newton inversion method from the complex resistivity data with added noise. The results (Fig. 3) showed the inversion curve was close to the model curve, which indicated that this method was feasible.

\subsection{Shale Rock IP Parameters Inversion}

The measured complex resistivity of the shale sample $205^{\#}$ from Weiyuan area was used to invert the IP parameters in order to verify the effectiveness of the inversion method. The mineral composition of the shale rock sample is shown in Table 2.

The shale rock sample was subjected to a complex resistivity test under the condition of clean water saturation, the electrical conductivity of which is $0.05 \mathrm{~S} / \mathrm{m}$, and the testing frequency ranged from 0.01 to $100 \mathrm{~Hz}$. Using the observed amplitude and phase for inversion, we obtained the IP true parameters as: $\rho_{0}=16.40(\Omega \cdot \mathrm{m}), m=0.1675$, $\tau=3.01 \times 10^{-4}(\mathrm{~s}), c=0.2698$. The observed data and the 

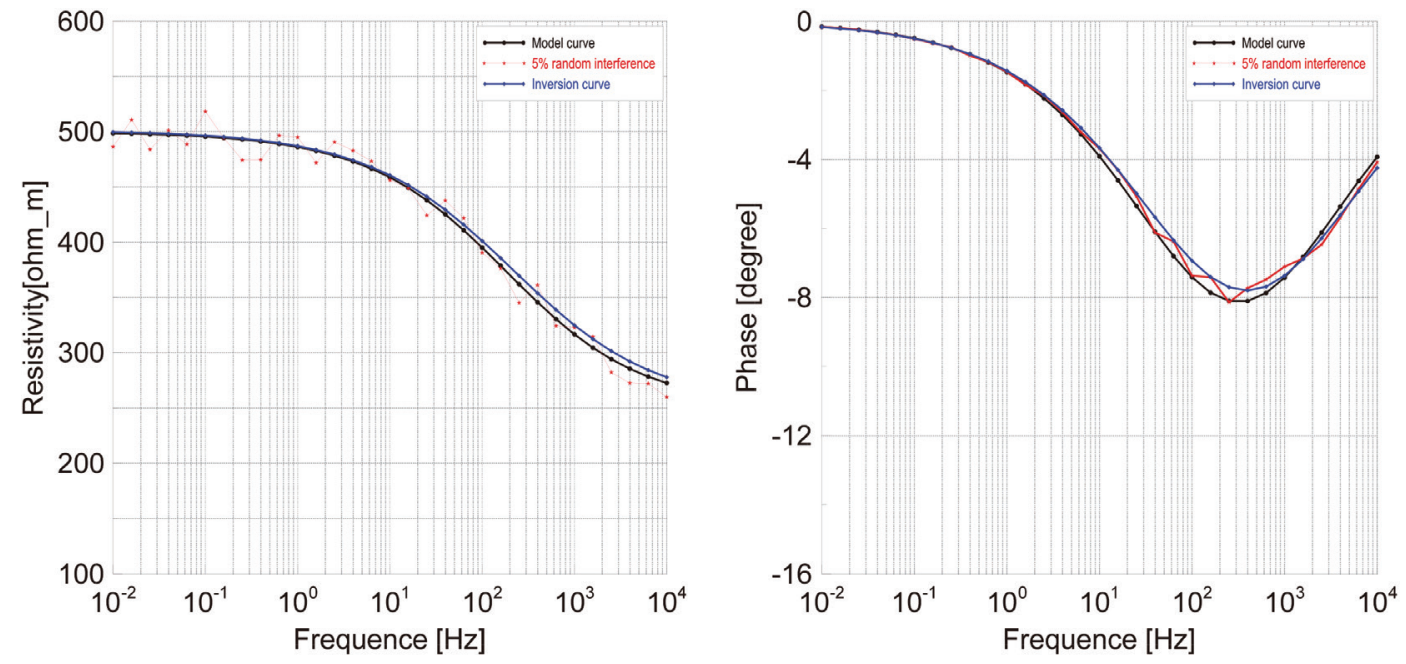

Fig. 3. Forward and inversion curve of Cole-Cole model.

Table 2. Core rock sample of 205 well in Weiyuan area.

\begin{tabular}{c|c|cccccc}
\hline \multirow{2}{*}{ Number } & \multirow{2}{*}{ Lithology } & \multicolumn{5}{|c}{ Mineral content (\%) } \\
\cline { 3 - 8 } & & Clay & Quartz & Plagioclase & Calcite & Dolomite & Pyrite \\
\hline 1 & shale rock & 36.5 & 34.0 & 5.5 & 10.8 & 10.1 & 3.1 \\
\hline
\end{tabular}

curve forwarded with the inverted IP parameters are shown in Fig. 4. The fitness of the inverted results to the observed data indicates that the method was feasible.

\section{DISCUSSION}

\subsection{Pyrite in Rich-Organic Shale}

Pyrite and Magnetite are the typical minerals which lead to strong induced polarization. Measurements of richorganic shale samples collected from the outcrop and the well in southern China showed that the organic-rich shale reservoir stratums were characterized by low resistivity and high polarization, and at the same time the rich content of pyrite had also been discovered (Yan et al. 2014). Pyrite is formed under reducing conditions at the subsurface when free iron and sulphide are available and is a characteristic mineral in rich organic sedimentation. According to Veeken et al. (2009), its organic reaction is given by:

$\mathrm{H}_{2} \mathrm{~S}+\mathrm{Fe}^{2+}+2 \mathrm{OH}^{-} \rightarrow \mathrm{FeS}_{2}+\mathrm{H}_{2} \mathrm{O}$

It is stimulated by the following reaction between freely dissolved ions in the pore water with the help of methane to form carbonate:

$\mathrm{CH}_{4}+\mathrm{Ca}^{2+}+\mathrm{SO}_{4}^{2-} \rightarrow \mathrm{CaCO}_{3}+\mathrm{H}_{2} \mathrm{~S} \uparrow+\mathrm{H}_{2} \mathrm{O}$
In addition, biodegradation and bacterial activity may give rise to an organic origin of pyrite in the sedimentary pile. It is proved empirically that a significant enrichment in pyrite often is related to hydrocarbon occurrences at deeper levels. From Eqs. (6) and (7), we can see hydrocarbons are a contributing factor to the formation of pyrite. The shale gas reservoir is characterised by low porosity, low sonic velocity, low density, and low permeability, which guarantees the seal of the hydrocarbon accumulation is better than other kinds of rocks thereby little hydrocarbons along with hydrogen sulfide can escape. This also means that the stronger reduced zone appears in the rich organic shale which has increased the intensity of electrochemical reactions, the higher the TOC is, the more pyrite creates.

Furthermore, 17 cores in the shale gas reservoir stratum from Zhao 104* well were analysed for TOC, the properties of the well rock samples are shown in Table 1. The contents of TOC and pyrite are shown in Fig. 5. The results showed that the amount of TOC was in direct proportion to the percentage of pyrite which had something to do with the organic matter. As alluded to earlier, the pyrite in the shale was polarized, so the TOC composition could be predicted by chargeability.

\subsection{TOC Prediction}

The complex resistivity of all the samples were measured by SI1260 impedance analyzer at normal temperature 

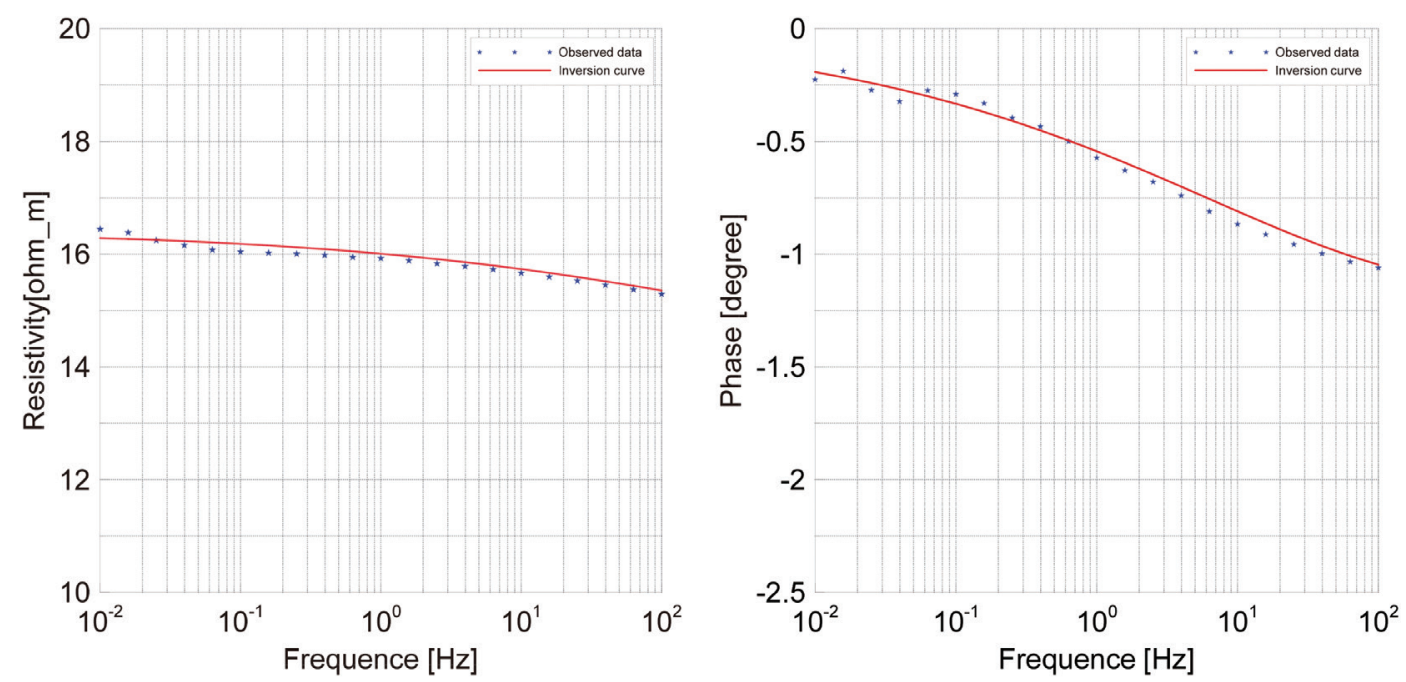

Fig. 4. The complex resistivity amplitude and phase of the 205\# shale rock sample and the inversion curve.

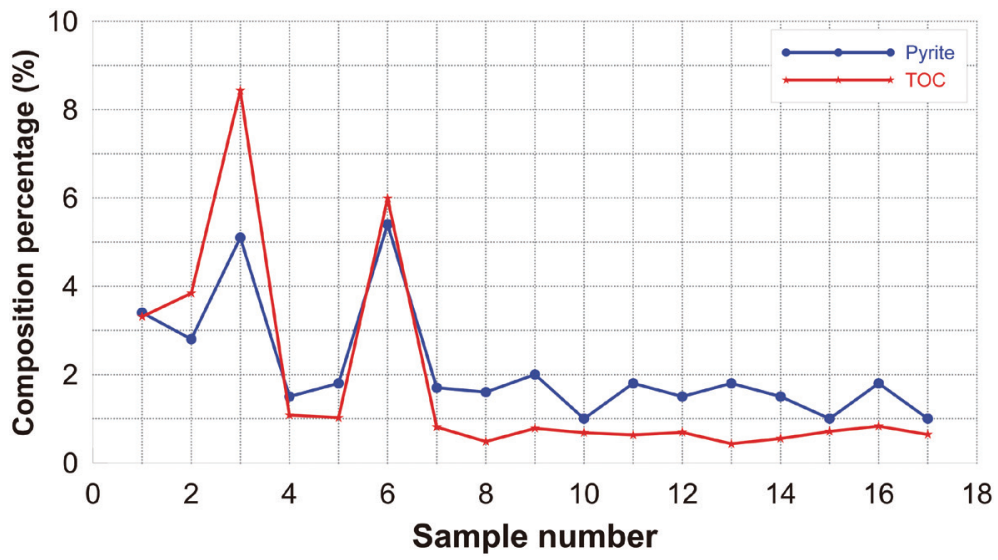

Fig. 5. TOC and pyrite contents of 17 shale cores.

and pressure. The measuring frequency ranged from 0.01 to $100 \mathrm{~Hz}$. After we completed the laboratory complex resistivity measurement, the polarization parameter $\left(\rho_{0}, m, \tau\right.$, $c$ ) of the samples could be obtained by the Gauss-Newton inversion method. Figures 6 and 7 are the cross-plot between pyrite content and polarization parameters. The results showed that most shale with pyrite content below $2 \%$ had the chargeability lower than $25 \%$. The chargeability of the rare shale with high pyrite content was more than $30 \%$, even up to $40 \%$. The shale with pyrite content below $2 \%$ had the resistivity between $70-200 \Omega \cdot m$ and the rare shale with high pyrite content had the resistivity less than $30 \Omega \cdot \mathrm{m}$. Based on the inverted IP parameters and the measured content of pyrite, we observed that the content of pyrite was negatively correlated to resistivity (Fig. 6) and positively correlated to chargeability (Fig. 7). The quantitative relationships between pyrite and resistivity are not obvious, but the correlated relationships are apparent, and the quantita- tive relationships between pyrite and chargeability clearly observed.

Based on the inverted chargeability and TOC measurements of the samples from the research area, the cross-plot between chargeability and TOC was established as shown in Fig. 8. The quantitative relationship was given as:

$\mathrm{TOC}=3.295 \ln (m)+10.428$

It is possible that TOC could be quantitative predicted by the above empirical formula, which laid the foundation for sweet spots detection with CSEM.

\subsection{Brittleness Prediction}

The mineral composition of shale reflects the sedimentary environment and conditions. It also determines 


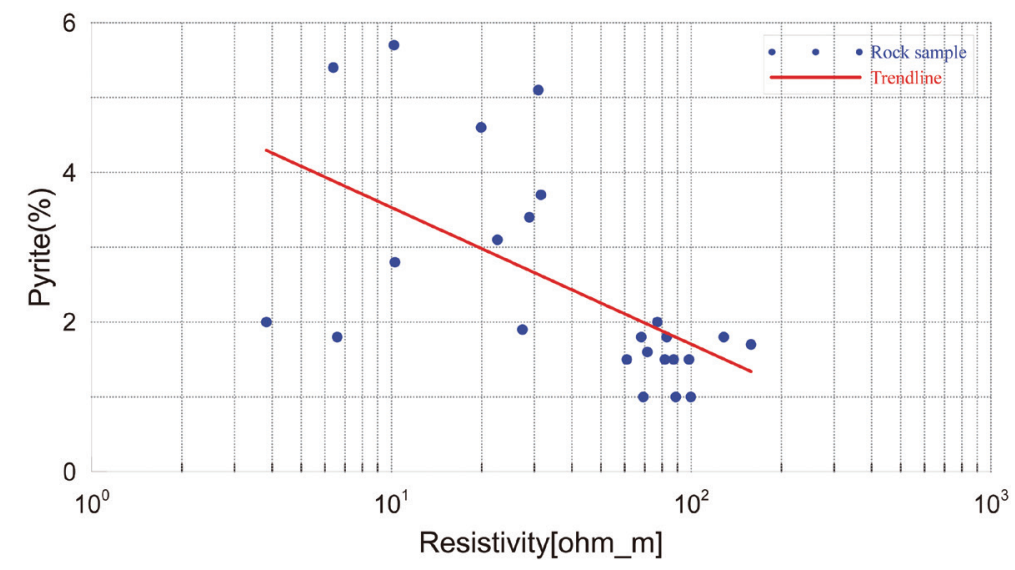

Fig. 6. Cross-plot between pyrite content and resistivity.

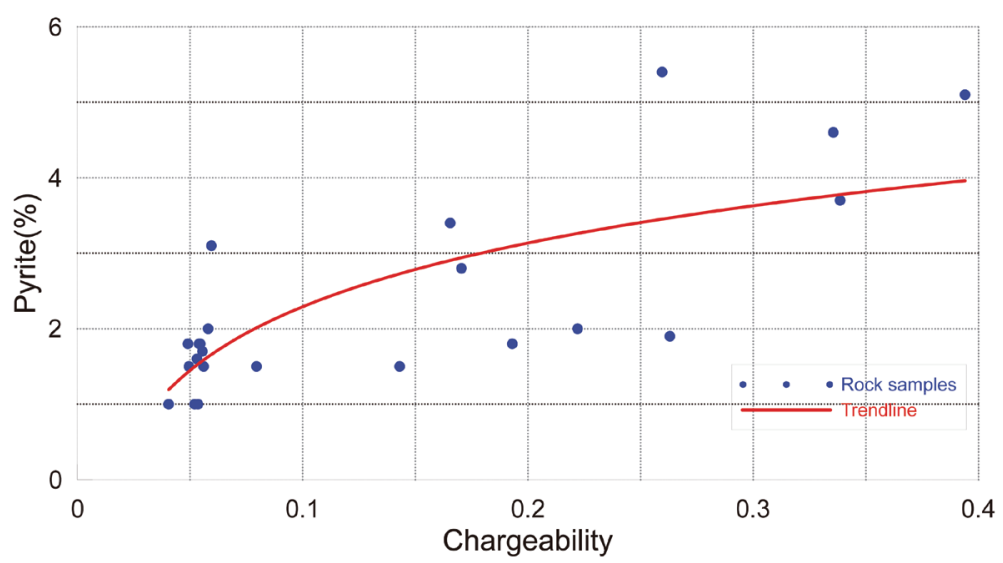

Fig. 7. Cross-plot between pyrite content and chargeability.

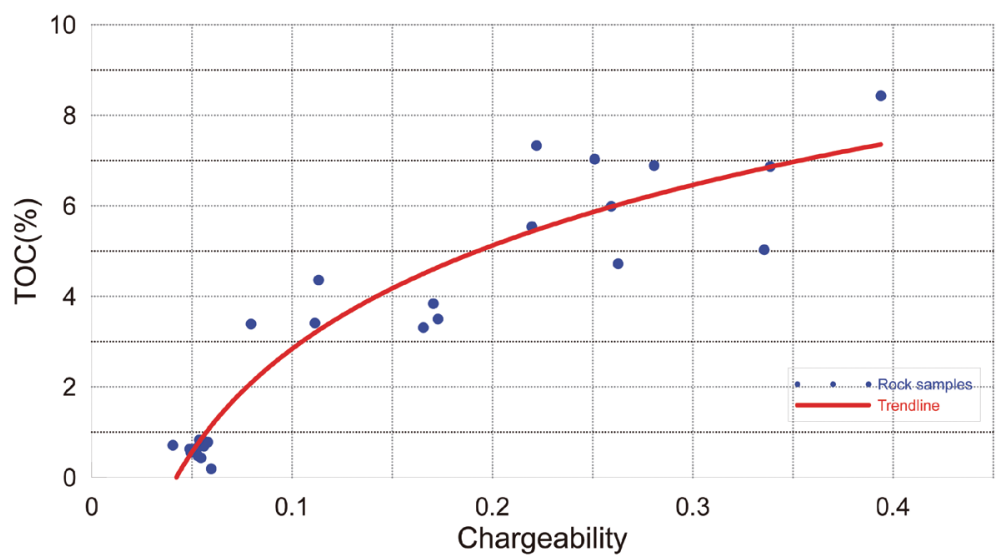

Fig. 8. Relationship between TOC and Chargeability. 
the brittleness index of shale, and affects the fracturing and exploitation. Therefore, investigating the relationship of brittleness index and electrical parameters has an important significance from the shale mineral type perspective and relative content.

Brittleness index is defined as: the ratio of Siliceous minerals (quartz, feldspar, dolomite, and pyrite) percentage and the sum of siliceous minerals, carbonate minerals and clay minerals percentage (Ren et al. 2018), given by B as:

$B=\frac{W_{q u a}+W_{f e l}+W_{d o l}+W_{p y r}}{W_{\text {total }}}$

Where $B$ is brittleness index, $W_{\text {qиа }}$ is the percentage of quartz, $W_{f e l}$ is the percentage of feldspar, $W_{d o l}$ is the percentage of dolomite, $W_{p y r}$ is the percentage of pyrite, and $W_{\text {total }}$ is the percentage of all mineral components.

In Fig. 1, the quartz and feldspar mineral content of shale showed they are high in Qiongzhusi formation and that its average percentage is $60 \%$. By contrast the longmaxi formation is lower. Based on the Eq. (9), and the relationship of pyrite and polarization parameters (Figs. 6 and 7), we could predict the brittleness index with the CSEM method.

Figures 9 and 10 showed the cross-plot between brittleness index and electrical parameters (resistivity and chargeability). The results indicate that the quantitative relation between brittleness index and IP parameters (resistivity and chargeability) were great. The quantitative relation model of brittleness index with resistivity and chargeability were as follows.

$B=-8.462 \ln (R)+83.46$

$B=18.772 \ln (m)+94.384$

\section{CONCLUSION}

The content of pyrite in organic-rich shales is higher than that of the surrounding rocks because of the higher content of TOC according to the geochemical theory and shales component analysis. The complex resistivity measurement showed that the organic-rich shale was characterized by

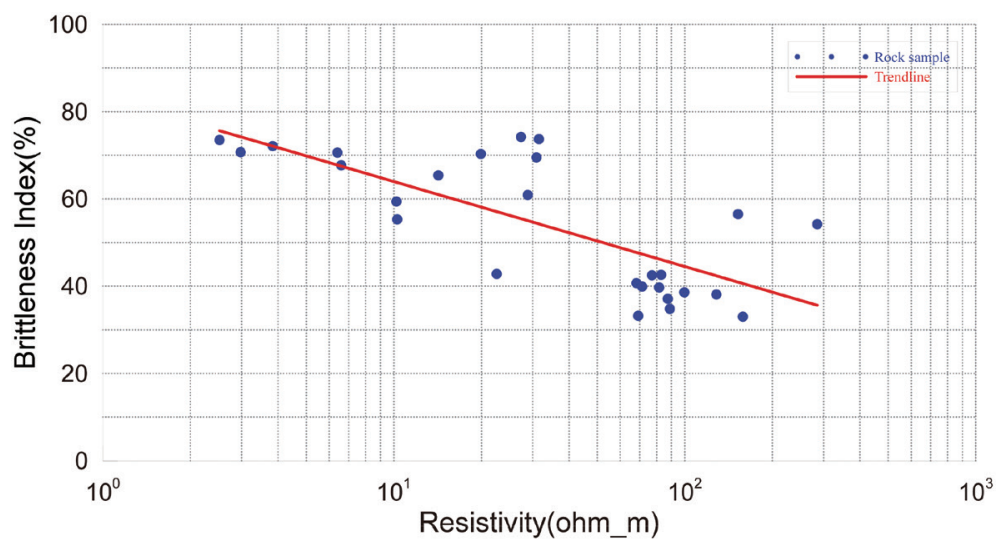

Fig. 9. Cross-plot between brittleness index and resistivity.

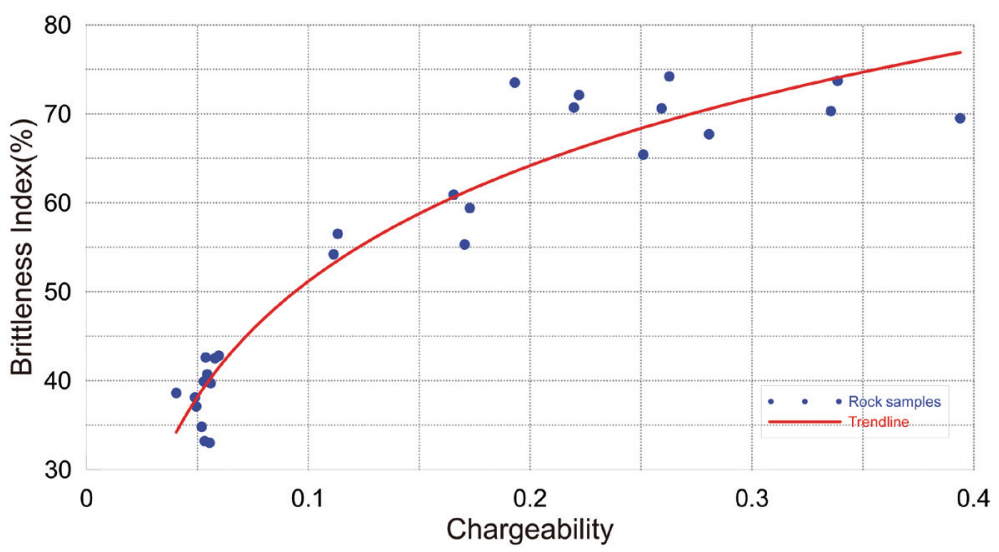

Fig. 10. Cross-plot between brittleness index and chargeability. 
low resistivity and high chargeability. Clearly pyrite is an indicative mineral of induced polarization and also a brittleness mineral. Thus, complex resistivity has correlations with TOC and brittleness, which provides a platform to predict the sweet spot characteristic parameters of shale with complex resistivity. The quantitative relational models among TOC content, brittleness index and complex resistivity inversion parameters (resistivity and chargeability) respectively have been established through the experiments. And these models are of great significance for the prediction of shale sweet spot by CSEM.

Acknowledgements The authors wish to acknowledge the support by the National Key R\&D Program of China (2017YFC0601804), the National Natural Science Foundation of China (41774082), and the science research and technology development project (2017D-5006-16), CNPC.

\section{REFERENCES}

Chopra, S., R. K. Sharma, J. Keay, and K. J. Marfurt, 2012: Shale gas reservoir characterization workflows. SEG Technical Program Expanded Abstracts, Society of Exploration Geophysicists, 1-5, doi: 10.1190/Segam2012-1344.1. [Link]

Cole, K. S. and R. H. Cole, 1941: Dispersion and absorption in dielectrics. I. Alternating current characteristics. J. Chem. Phys., 9, 341-351, doi: 10.1063/1.1750906. [Link]

Li, J. M., 1994: IP Method, Geology Publish House, Beijing. (in Chinese)

Luo, Y. Z. and G. Q. Zhang, 1988: Theory of SIP, Geology Publish House, Beijing. (in Chinese)

Nie, X., 2014: Digital core modeling and numerical study of electrical conductivity of shale gas reservoir rock. Ph.D. Thesis, China University of Geosciences, Beijing, China.

Passey, Q. R., S. Creaney, J. B. Kulla, F. J. Moretti, and J. D. Stroud, 1990: A practical model for organic richness from porosity and resistivity logs. AAPG Bull., 74, 1777-1794.

Pelton, W. H., S. H. Ward, P. G. Hallof, W. R. Sill, and P. H. Nelson, 1978: Mineral discrimination and removal of inductive coupling with multifrequency IP. Geophysics, 43, 588-609, doi: 10.1190/1.1440839. [Link]

Ren, Y., H.Cao, F. C. Yao, M. H. Lu, Z. F. Yang, and X. M. $\mathrm{Li}, 2018$ : Brittleness and friability prediction for tight oil reservoir in Jimsar Sag, Junggar Basin. OGP, 53, 511-519.

Schön, J. H., 2004: Physical Properties of Rocks: Funda- mentals and Principles of Petrophysics, Elsevier Science, $600 \mathrm{pp}$.

Streich, R., M. Becken, and O. Ritter, 2010: Imaging of $\mathrm{CO}_{2}$ storage sites, geothermal reservoirs, and gas shales using controlled-source magnetotellurics: Modeling studies. Geochemistry, 70, 63-75, doi: 10.1016/j.chemer.2010.05.004. [Link]

Tsai, L. L., H.-J. Hsieh, H.-T. Lee, and L.-C. Sun, 2008: Relationships between organic material and thermal maturity derived from coal and C-shale samples. Terr. Atmos. Ocean. Sci., 19, 489-495, doi: 10.3319/ TAO 2008.19.5.489(TT). [Link]

Veeken, P. C., P. J. Legeydo, Y. A. Davidenko, E. O. Kudryavceva, S. A. Ivanov, and A. Chuvaev, 2009: Benefits of the induced polarization geoelectric method to hydrocarbon exploration. Geophysics, 74, B47-B59, doi: 10.1190/1.3076607. [Link]

Wang, J. Y., 2002: Inversion Theory in Geophysics, Higher Education Press, Beijing.

Wang, Y. C., H. D. Huang, Y. Z. Ji, and Y. Zheng, 2013: Research on geophysical feature and sweetness predication method of shale gas. SEG Technical Program Expanded Abstracts, Society of Exploration Geophysicists, 3201-3205, doi: 10.1190/segam2013-0829.1. [Link]

Wilson , J., 2003: Field Geophysics, British Publication Library Cataloguring in Publication Data.

Xiang, K., W. B. Hu, L. J. Yan, C. H. Zhang, W. W. He, X. G. Tang, and X. J. Liu, 2014: Complex resistivity dispersion characteristics of shale samples in Sichuan and Guizhou area. Oil Geophysical Prospecting, 49, 1013-1019. (in Chinese)

Xiang, K., L. J. Yan, H. Hua, W. B. Hu, X. G. Tang, and X. J. Liu, 2016: Relationship analysis between brittle index and electrical properties of marine shale in South China. Geophysical Prospecting for Petroleum, 55, 894-903, doi: 10.3969/j.issn.1000-1441.2016.06.015. (in Chinese) [Link]

Yan, L. J., K. Xiang, P. F. Lei, X. J. Liu, and Z. G. Wang, 2014: Study on the induced polarization model in the exploration for shale gas in southern China. SEG Technical Program Expanded Abstracts, Society of Exploration Geophysicists, Denver, Colorado, 912-916, doi: 10.1190/segam2014-0186.1. [Link]

Zhang, C. H., X. J. Liu, L. F. He, W. W. He, Y. M. Zhou, Y. S. Zhu, Z. W. Cui, and X. H. Kuang, 2013: A study of exploration organic rich shales using Time-Frequency Electromagnetic Method (TFEM). Chinese J. Geophys., 56, 3173-3183, doi: 10.6038/cjg20130930. (in Chinese) [Link] 